\title{
The Linear, Non-linear Measurements, Analysis and Evaluation for the Design of Ultra-Wideband Low Noise Amplifier
}

\author{
Pramod K. B. \\ PhD Student of \\ JAIN University \\ Asst Prof. in EXTC \\ Dept. at MCT's RGIT, Mumbai
}

\author{
Kumaraswamy H. V. \\ Dept of Telecommunication \\ R. V. C. E, Bangalore, India
}

\begin{abstract}
This paper exhibits an examination, configuration, design to measure nonlinear characteristics of low noise amplifier(LNA) furthermore investigation, assess those estimations in the AWR microwave office Tool. A large portion of the critical aspects of LNA will be in linear measurements and which is composed, designed and simulated for the ultra LNA from $3 \mathrm{GHz}$ to $10 \mathrm{GHz}$. In this proposed work the methodology has made to address nonlinear and linear measurements to the restricted band LNA which be working in $820-960 \mathrm{MHz}$ ISM band. The work provides the required information about LNA design by using two different advance measurement techniques. First techniques are by using two tone harmonic balance source input and second one is uses just by two port $50 \Omega$ lossless line. A simulation setup is made to measure the characteristics of LNA by using spectrum rectangular display type with power harmonic components. In this paper, three circuits schematic of the designed LNA are discussed with corresponding measurements. Finally, author designed ultrawideband LNA from the bandwidth $3 \mathrm{GHz}$ to $10 \mathrm{GHz}$ and elaborates how nonlinear measurements changed the way of LNA design to validate and construction at higher frequencies.
\end{abstract}

\section{Keywords}

Nonlinear measurements, microwave circuits, two-tone measurements, harmonic balance, Scattering parameters and Low noise amplifier (LNA).

\section{INTRODUCTION}

In the growth of communication world, the wireless sensor networks (WSNs) have becoming highly seeking after in extremely great in number of applications likely RADAR, Defence, health-care, environmental monitoring, industrial settings, and agriculture. LNA performance has a strong impact with high interesting on the gain, bandwidth, Noise figure and return loss in the receiver systems. The aim of this proposed work is to have contradictions with regularly used linear measurements and nonlinear measurements in LNA circuit in ISM bands.

In this paper, the circuit design method of proposed ISM band $820-960 \mathrm{MHz}$ low-noise amplifier and also Ultra-wideband LNA using AWR tool with non-linear measurement presented in sections III Finally, the conclusion is summarized in section IV and $\mathrm{V}$.

\section{RESEARCH BACKGROUND}

During the last decades, various LNA design circuits have been proposed and presented. The most popular LNA design is based on Hybrid Microwave Integrated Circuit (HMIC) technology up to $10 \mathrm{GHz}$ frequency band. So in this section various proposed designs are discussed with their benefits and limitations with respect to measurement techniques.

Sombrin,[3] discussed two important measurements likely NPR (noise power ratio) and EVM (error vector magnitude) are characterize linear or non-linear distortions and degradations in digital modulators, RF and microwave amplifiers and transmission links. Also examines the necessary conditions for these two measurements (or simulations) to give the same value for this equivalent noise. Teppati, Ferrero, Camarchia, Neri, \& Pirola,[4], in their work completes the sequence started with articles of Camarchia et al. [1] previously work which presented the most important aspects of RF and microwave linear and non-linear measurements. In basic load-pull systems, the device under test (DUT) is driven by a single tone microwave source while the DUT performance metrics, typically output power and power added efficiency (PAE), are monitored as a function of the load and/or source terminations. Also describe two of the most advanced measurement techniques that can provide the required information for amplifier design are first technique is the multi-tone/complex modulation load-pull and second measurement technique is the time domain waveform loadpull. (Camarchia, Teppati, Corbellini, \& Pirola, [1] addresses the problems in microwave non-linear measurements and discusses techniques to synthesize loads, the most used nonlinear measurement techniques, and harmonic load-pulling. The vector network analyzer (VNA) is the core instrument used in the non-linear characterization scenario. Schreurs, [2], discusses the capabilities of vector non-linear microwave measurements. It starts off with a historical review on the development of such instrumentation and elaborates on how vector non-linear measurements changed the way in which models for non-linear microwave devices are validated and constructed, broadened physical understanding, and impacted microwave circuit design.

\section{DESIGN AND MEASUREMENTS}

This section gives the information about the importance of nonlinear measurements in microwave amplifier especially with respects to LNA and power amplifier. This proposed work gives clear idea about how to make non-linear measurements in AWR microwave tool.

For the successful non-linear measurements of the LNA require to be designed three or more number of schematics 
because Nonlinearities model are prepared by a numerous polynomial and clipping function. In which those functions provide the correct saturation, harmonics and intermodulation characteristics regardless of the relative values of IP3 and $\mathrm{P} 1 \mathrm{~dB}$. The controlled current source $\mathrm{f}(\mathrm{v})$ is modelled by a polynomial:

$$
\begin{gathered}
f(v)=a_{1} v+a_{2} v^{2}+a_{3} v^{3}+a_{4} v^{4} \\
+\cdots \ldots \ldots(1)
\end{gathered}
$$

The above polynomial models describe intermodulation distortion through $\mathrm{N}$ order. Generally polynomial will be considered up to order 3 . The values of the coefficients are derived from the specified intercept points.

\subsection{Schematic 1}

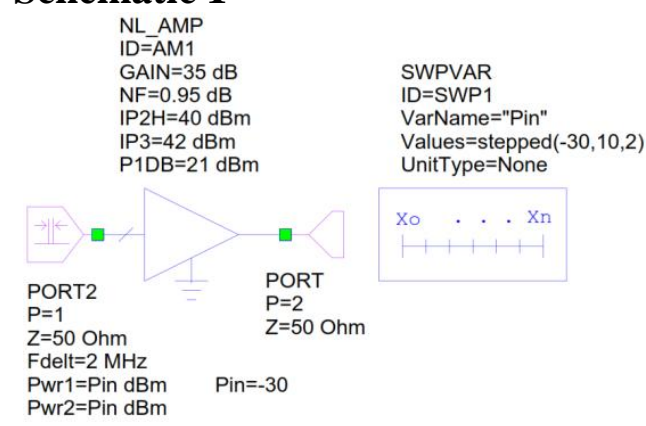

Fig 1. shows prepared schematic with components NL_AMP, SWPVAR, Port 2 and Port for the LNA module.

The one- $\mathrm{dB}$ compression point is thing that constitute more problem to prepare model. One cause of compression in a microwave LNA is clipping of the when DC bias power is inadequate to provide output for corresponding input waveforms power. Theoretically, even if the LNA is perfectly linear for small signals which implies that $\mathrm{a} 2=0, \mathrm{a} 3=0$ so on in the polynomial. The Compression are caused by the inherent small-signal nonlinearities in $\mathrm{f}(\mathrm{v})$. In such cases, a cubic polynomial is not acceptable in quality to model compression, and unless other means are used, the model becomes very poor and lacks with sufficient data above the 1dB compression point.

To avoid these state of difficulty, the amplifier model calculates the $1 \mathrm{~dB}$ compression point according to both criteria and uses the one that represents the lower of the two compression levels. If the LNA's compression is caused by clipping, a clipping function is used with the value set appropriately. [9] Seems to contradict that if compression is caused by the nonlinearities in $f(v)$, those are allowed to provide compression. The clipping level is then set somewhat higher, to provide the correct behavior in hard saturation. The transition between these two conditions is approximately 10 $\mathrm{dB}$ below the third-order intercept point, IP3. Therefore, if P1DB < IP3 - 10, the amplifier saturates on clipping, while, for higher values, the nonlinearities of $\mathrm{f}(\mathrm{v})$ dominate [10].

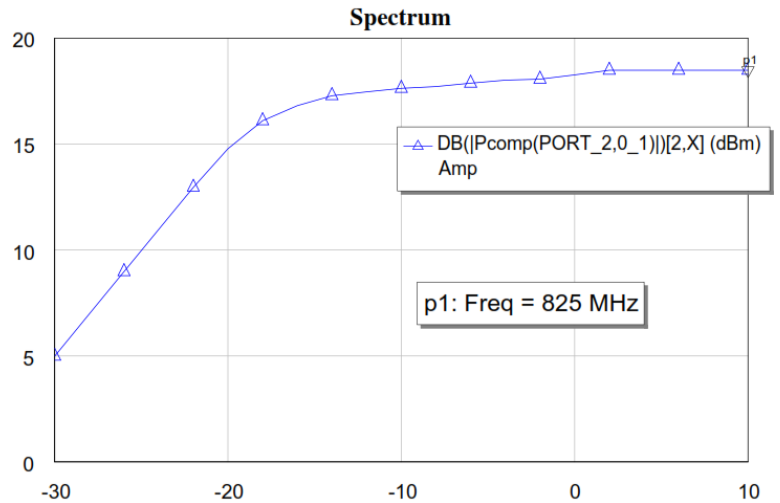

Fig 2. Shows power harmonic component in $\mathrm{dB}$ at $825 \mathrm{MHz}$ for the different value of the input power in $\mathrm{dBm}$

The Power harmonic component measurement is used to measure a harmonic component of the power measured at a frequency of $825 \mathrm{MHz}$ in the designed LNA circuit. The power value is returned as the complex magnitude of the RMS power component at the harmonic frequency with integral from minus minimum to positive maximum, to obtain the DC power, use a harmonic index of zero. Also to obtain the power at the fundamental frequency use a harmonic index of one.

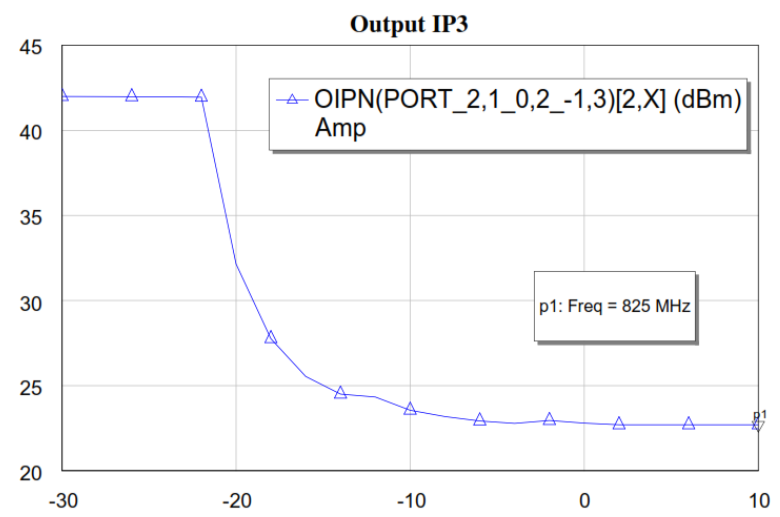

Fig 3. Shows the third order intercept point of the designed LNA Circuit

Output third order intercept point(OIP3) computed by having multi-tone excitations but result in figure 3 is displayed for the single frequency point at $825 \mathrm{MHz}$. [11] The intercept point is the point at which a linear extrapolation of the fundamental power and the power in the intermodulation product intersect each other. When shown as output power in $\mathrm{dBm}$ versus input power in $\mathrm{dBm}$.

\subsection{Schematic 2}

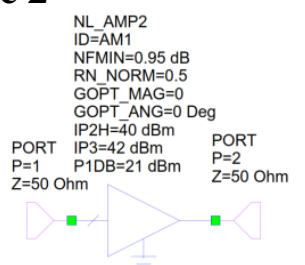

Fig 4. shows prepared schematic with two passive terminations of $50 \Omega$ for the LNA module

The above figure 4 is prepared by using two passive terminating port $50 \Omega$ for the LNA module which is incorporated intercept points value and required harmonics, NFmin and Rn_Norm data. 


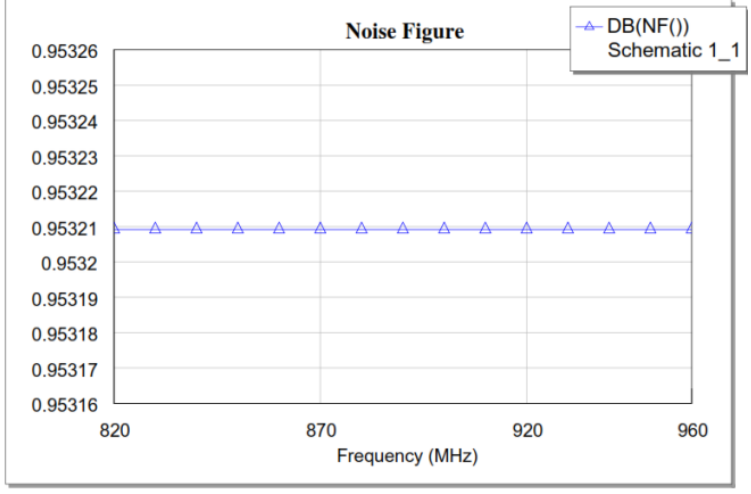

Fig 5. Shows the Noise figure of the prepared LNA module

$\mathrm{NF}=\mathrm{NFmin}+\frac{\mathrm{Rn}}{\mathrm{Gs}} *\left[(\mathrm{Gs}-\mathrm{Gopt})^{2}+(\mathrm{Bs}-\mathrm{Bopt})^{2}\right]$

where Ys $=\mathrm{Gs}+\mathrm{jBs}$ and Yopt $=$ Gopt $+\mathrm{jBopt}, \quad \mathrm{NFmin}=$ lowest possible noise factor Yopt $=$ optimum source admittance for minimum noise

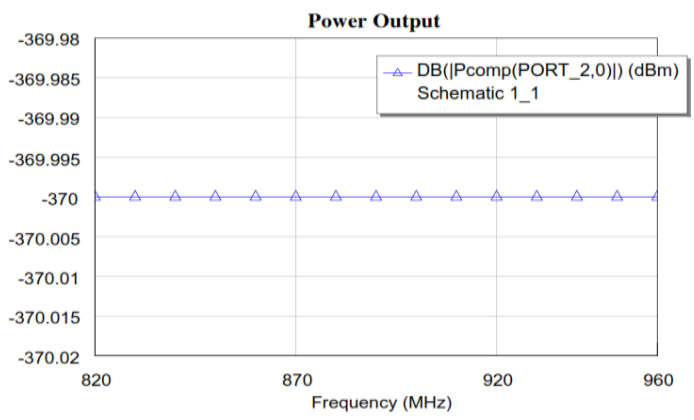

Fig 6. Shows output power component in dB over complete interested band for the different value of the input power in $\mathbf{d B m}$

\subsection{Schematic 3}

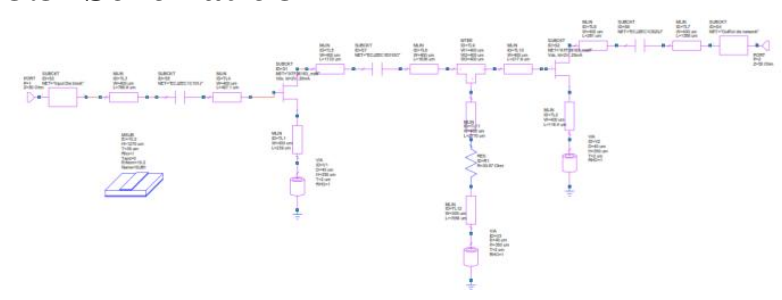

Fig 7. Shows complete schematic of the designed LNA circuit for linear measurements

Figure 7 gives the complete schematic of the designed LNA which is having bandwidth of 3 to $10 \mathrm{GHz}$.

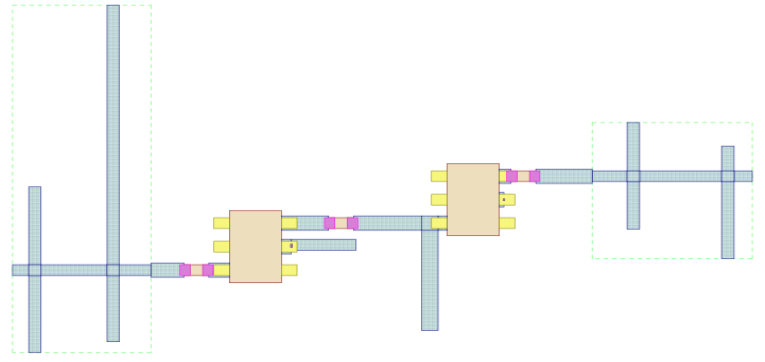

Fig 8. Complete 2D layout of the proposed ultra-wideband LNA
$\mathrm{K}$ is the stability factor for a two-port, defined as:

$$
\mathrm{K}=\frac{1-\left|S_{11}\right|^{2}-\left|S_{22}\right|^{2}+|\Delta|^{2}}{2\left|S_{12} S_{21}\right|}
$$

where

$\Delta=\mathrm{S}_{11} \mathrm{~S}_{22}-\mathrm{S}_{12} \mathrm{~S}_{21}$

Figure 8 shows the corresponding layout of the designed circuit of the ultra-wideband LNA. Figure 9 shows its clear picture in 3D viewer.

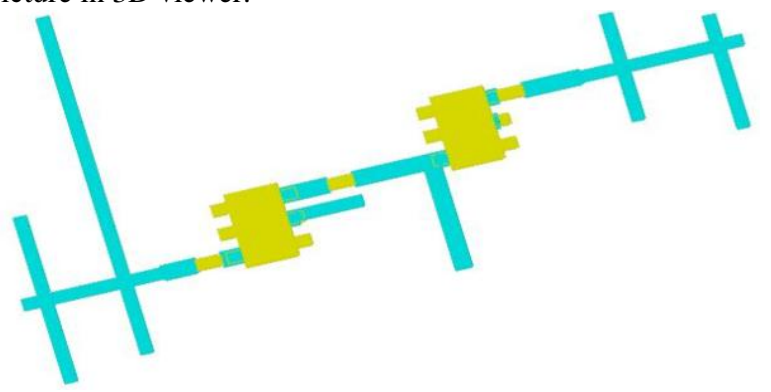

Fig 9. Complete 3D layout of the proposed ultrawideband LNA

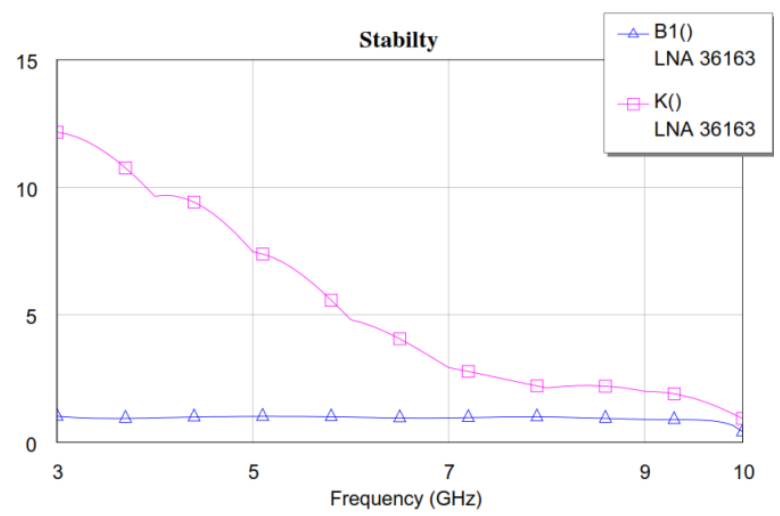

Fig 10. Shows the stability Rollet factor $K$ and auxiliary factor.

Since the denominator can be arbitrarily small, and large values of $\mathrm{K}$ are of no significance, this measurement has a maximum limit of 1000 , or 30 if plotting in $\mathrm{dB}$. The necessary and sufficient conditions for unconditional stability are: $\mathrm{K}>1$ and B1>0. This measurement applies to 2-port circuits only.

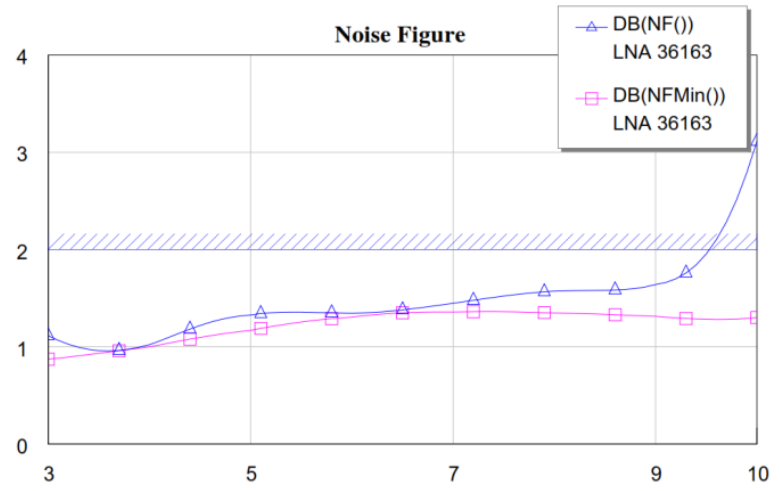

Fig 11. Shows noise figure and NFmin characteristics of the ultra-wideband LNA 


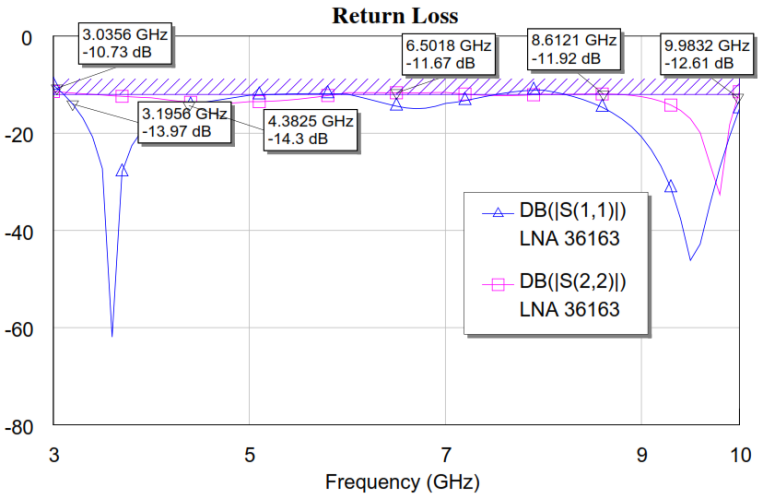

Fig 12. Shows input return loss(S11) and output return loss(S22) characteristics of the ultra-wideband LNA

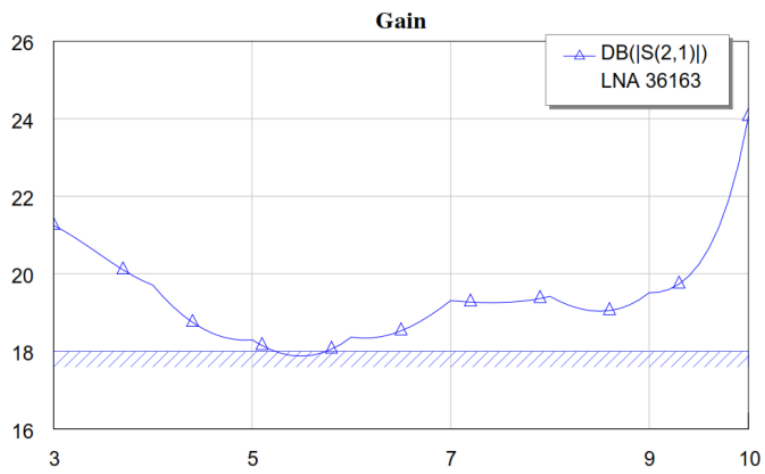

Fig 13. Shows transducer gain (S21) in $\mathrm{dB}$ of the ultrawideband LNA

\section{SUMMARY}

Table 1. Comparison of the proposed work results to recent published work

\begin{tabular}{|l|l|l|l|l|}
\hline Reference & $\begin{array}{l}\text { Bandwidth } \\
(\mathbf{G H z})\end{array}$ & $\begin{array}{l}\text { Noise } \\
\text { Figure } \\
\text { in dB }\end{array}$ & $\begin{array}{l}\text { Gain } \\
\text { in dB }\end{array}$ & $\begin{array}{l}\text { Return } \\
\text { Loss in } \\
\text { dB }\end{array}$ \\
\hline$[5]$ & $0.5-6$ & $<3$ & $>30$ & $\begin{array}{l}\text { Not } \\
\text { considered }\end{array}$ \\
\hline$[6]$ & $3-11$ & $\begin{array}{l}<3.37 \\
\pm 0.15\end{array}$ & $\begin{array}{l}>17.74 \\
\pm 0.64\end{array}$ & -8.2 \\
\hline$[7]$ & $3-10$ & $<5$ & $>16.78$ & -14 \\
\hline$[8]$ & $2.8-10.6$ & $<3.2 \pm$ & $>12.32$ & -7.45 \\
& & 0.2 & \pm 1.07 & \\
\hline $\begin{array}{l}\text { This } \\
\text { Proposed } \\
\text { work }\end{array}$ & $3-10$ & $<2$ & $>18$ & $<-10 \mathrm{~dB}$ \\
\hline
\end{tabular}

\section{CONCLUSION}

The linear, non-linear characteristics estimations of which been working in 820-960 MHz ISM band LNA clearly discussed in this paper. All examinations, outline of low noise amplifier, investigation and assessment are done in the industrial standard AWR microwave office tool. In this proposed work the endeavour has made to address nonlinear and linear measurements to the narrow band low noise amplifier with the assistance of rectangular display type with essential estimations like Gain, NF, RL and PAE. The work gave the required data about LNA design by utilizing two diverse development estimation procedures and key characteristics. The three circuits schematics of the outlined LNA are examined with comparing estimations and demonstrated deviations, changes in schematic level. At last, author elaborates and explains the linear, nonlinear estimations order of LNA configuration to accept and build at higher frequencies.

\section{ACKNOWLEDGMENT}

This work is supported by MCT's Rajiv Gandhi Institute of Technology, Mumbai and also authors would like to thank Dr. Udhav Bhosle, Principal of RGIT, Chairman, Board of Studies in EXTC Engineering, University of Mumbai for significant support and encouragement for this research work. The authors would like to special thanks for Prof. K. T Srirangaraj , Dr. TGS Moorthy, Prof. Chandrashekar K. CET, Jain University, Bangalore and Mr. Manjunatha Reddy H. V Technical Manager, RF and $\mu \mathrm{W}$ division, Icon Design Automation Pvt. Ltd. for their valuable guidance.

\section{REFERENCES}

[1] Camarchia, V., Teppati, V., Corbellini, S., \& Pirola, M. (2007). Microwave Measurements Part II Non-linear Measurements. IEEE Instrumentation \& Measurement Magazine, vol. 10, no. 3, 34-39.

[2] Schreurs, D. (2010). Applications of vector non-linear microwave measurements, IET Microwaves, Antennas \& Propagation, vol. 4, no. 4 doi: 10.1049/ietmap.2009.0479, 421-425.

[3] Sombrin, J. B. (2011). On the formal identity of EVM and NPR measurement methods: Conditions for identity of error vector magnitude and noise power ratio. Microwave Conference (EuMC), 2011 41st European, Manchester, 337-340.

[4] Teppati, V., Ferrero, A., Camarchia, V., Neri, A., \& Pirola, M. (2008). Microwave measurements - Part III: Advanced non-linear measurements. IEEE Instrumentation \& Measurement Magazine, vol. 11, no. 6, 17-22.

[5] B. R. Vidhale and M. M. Khanapurkar, "Design of ultra wideband low noise amplifier with the negative feedback using micro strip line matching structure for multiple band application and its simulation based performance analysis," 2016 International Conference on Wireless Communications, Signal Processing and Networking (WiSPNET), Chennai, India, 2016, pp. 1845-1848

[6] H. Karrari, H. F. Baghtash and E. N. Aghdam, "A 3 $11 \mathrm{GHz}$ current-reuse low noise amplifier for ultrawideband recievers," 2016 Eighth International Conference on Ubiquitous and Future Networks (ICUFN), Vienna, 2016, pp. 563-567. doi: 10.1109/ICUFN.2016.7537095

[7] H. Sathwara and K. Shah, "Design of low power CMOS low noise amplifier using current reuse technique," 2015 5th Nirma University International Conference on Engineering (NUiCONE), Ahmedabad, 2015, pp. 1-6. doi: 10.1109/NUICONE.2015.7449628

[8] H. Karrari and E. N. Aghdam, "A 2.8???10.6GHz lowpower low-noise amplifier for ultra-wideband recivers," 2015 2nd International Conference on Knowledge-Based 
Engineering and Innovation (KBEI), Tehran, 2015, pp. 908-911. doi: 10.1109/KBEI.2015.7436164

[9] C. k. Luo, P. S. Gudem and J. F. Buckwalter, "A 0.4-6$\mathrm{GHz}$ 17-dBm B1dB 36-dBm IIP3 Channel-Selecting Low-Noise Amplifier for SAW-Less 3G/4G FDD Diversity Receivers," in IEEE Transactions on Microwave Theory and Techniques, vol. 64, no. 4, pp. 1110-1121, April $2016 . \quad$ doi: 10.1109/TMTT.2016.2529598

[10] W. Gao, Z. Chen, Z. Liu, W. Cui and X. Gui, "A Highly Linear Low Noise Amplifier With Wide Range Derivative Superposition Method," in IEEE Microwave and Wireless Components Letters, vol. 25, no. 12, pp. 817-819, Dec. 2015. doi: 10.1109/LMWC.2015.2496793

[11] C. k. Luo, P. S. Gudem and J. F. Buckwalter, "0.4-6 GHz,17-dBm B1dB, 36-dBm IIP3 channel-selecting, low-noise amplifier for SAW-less 3G/4G FDD receivers," Radio Frequency Integrated Circuits Symposium (RFIC), 2015 IEEE, Phoenix, AZ, 2015, pp. 299-302. doi: 10.1109/RFIC.2015.7337764.

\section{AUTHOR PROFILE}

Mr. Pramod K B was born in Mysore, Karnataka, India in 1989. He is currently working as Assistant Professor in MCT's RGIT, Mumbai and also working towards $\mathrm{PhD}$ degree at JAIN University, Bangalore in Electronics Engineering. He received his B.E degree in Electronics and Communication from Dr.Ambedkar Institute of Technology, Bangalore Visvesvaraya Technological University in 2010, M.Tech degree in $\mathrm{R} F$ Communication from Jain University, Bangalore, in 2012 and He worked as R F Design trainee at Icon Design and Automation Pvt LtD and as visiting research scholar at University of Concordia, Montreal, Quebec, Canada. His research includes Design, Characterization And Optimization Of RF Passive Devices , Board Level Tuning And Optimization Of Matching Networks, Low Noise Amplifier , Power Amplifier, Circuit Linearization And HighEfficiency Design Techniques, Circuit Instability And Strategies.

Prof. Dr. Kumaraswamy H.V is currently working as Professor \& HOD in the Dept of Telecommunication Engineering, RVCE, and Bangalore. His research interests are Digital Signal Processing, Adaptive Signal Processing and Communication. He has got $\mathrm{PhD}$ from Visvesvaraya Technological University for the research work on Smart Antenna System using Dielectric lens. He is the author of the book titled "Signals \& Systems" Published by: SciTech Publication, Chennai. 